\title{
BRETTON WOODS SOB ATAQUE: \\ MUDANÇAS NA GOVERNANÇA ECONÔMICA INTERNACIONAL EM TEMPOS DE MULTILATERALISMO CONTESTADO
}

\author{
BRETTON WOODS UNDER ATTACK: CHANGES IN INTERNATIONAL ECONOMIC \\ GOVERNANCE IN TIMES OF CONTESTED MULTILATERALISM
}

Cristine Koehler Zanella

Universidade Federal do ABC, São Paulo, SP, Brasil E-mail: criskz.sma@gmail.com

Recebido em: 18.03.2017 - Aceito em: 16.04.2017

\section{RESUMO}

O domínio do Ocidente e especialmente dos Estados Unidos sobre o sistema internacional está se alterando neste século. A ordem institucional forjada ao final da Segunda Guerra Mundial se enfraquece, e as grandes organizações internacionais econômicas, nomeadamente Organização Mundial do Comércio, Banco Mundial e Fundo Monetário Internacional, não dão sinais de que estão se adaptando satisfatoriamente a essas transformações. Na disputa pela definição de quais serão e quem ditará as novas regras do jogo, Estados insatisfeitos organizam fóruns e coalisões de contestação. Este artigo se vale do conceito de multilateralismo contestado para descrever o cenário internacional que emerge dessas disputas, um ambiente no qual os Estados, embora insatisfeitos com a agenda ou a estrutura de governança do multilateralismo vigente, ainda preferem questioná-lo pela via multilateral, em detrimento de uma opção voltada ao unilateralismo ou ao bilateralismo. Argumentase também que, embora ares de nacionalismo tenham soprado mundo afora a partir dos Estados Unidos e de Estados europeus, esses movimentos não devem reverter a força das novas articulações multilaterais que vêm sendo construídas em outras frentes de contestação das instituições vigentes.

PALAVRAS-CHAVE: Multilateralismo contestado; Governança econômica internacional; Organização Mundial do Comércio; Banco Mundial; Fundo Monetário Internacional.

\section{ABSTRACT}

The West, and especially the United States dominance in the international system is changing in this century. The institutional order forged at the end of World War II weakened, and the major international economic organizations, such as the World Trade Organization, the World Bank, and the International Monetary Fund do not 
demonstrate to adapt satisfactorily to these transformations. In the dispute over who will be and who will dictate the new rules of the game, dissatisfied states organize forums and coalitions of contestation. This article relies on the concept of contested multilateralism to describe the international scenario emerging from these disputes, an environment in which states frustrated with the agenda or governance structure of existing multilateralism choose to question it multilaterally, instead of relying on unilateral or bilateral approaches. It is also argued that, although nationalist movements have recently emerged in the United States and European states, they should not reverse the strength of the new multilateral articulations that developing and emerging countries have been built on the current contending fronts.

KEYWORDS: Contested multilateralism; International economic governance; World Trade Organization; World Bank; International Monetary Fund.

\section{INTRODUÇÃO}

A estrutura da grande ordem econômica internacional está passando por transformações e questionamentos. A hegemonia ocidental está sendo alterada à medida que a ordem multilateral forjada ao final da Segunda Guerra Mundial se enfraquece. As organizações internacionais econômicas fazem parte desse processo. $\mathrm{Na}$ vertente comercial, a Organização Mundial do Comércio (OMC), que trabalha por meio de sucessivas rodadas de negociação, está paralisada na Rodada Doha há quase vinte anos. Na vertente financeira, o Banco Mundial (BM) e o Fundo Monetário Internacional (FMI) passaram por reformas após a crise de 2008/2009, mas não parecem ter convencido quanto ao sucesso dessas reformas nem quanto à importância do seu papel na atualidade. Junto à persistência desses impasses e insucessos, vias alternativas têm sido buscadas por Estados insatisfeitos.

As organizações mencionadas surgiram com as conferências de Bretton Woods, no final da Segunda Guerra Mundial, e seus objetivos declarados eram de criar condições econômicas que evitassem o retorno de um cenário propício à eclosão de conflitos militares. Para enfrentar problemas de liquidez dos Estados, foi criado o FMI; para fomentar projetos de desenvolvimento, foi criado o Banco Internacional de Reconstrução e Desenvolvimento (BIRD, que é o braço mais importante do Grupo Banco Mundial - GBM); e, para evitar uma nova onda de criação de medidas restritivas nacionais ao comércio e reduzir as barreiras existentes, foi assinado - Acordo Geral de Tarifas e Comércio (General Agreement on Tariffs and Trade GATT, transformado em Organização Mundial do Comércio - OMC, em 1995). 
A literatura já apontou ser comum que, no seu momento de nascimento, as organizações internacionais congelem determinada hierarquia de poder. Os privilégios, uma vez institucionalizados, são difíceis ou custosos de serem mudados porque os países que deles se beneficiam passam a deter posições de poder que Ihes permitem melhor resguardar seus interesses (Barnett e Duvall, 2005, p. 52; Fioretos, 2011, p. 387). Em que pesem as dificuldades de mudar a estrutura e a lógica de funcionamento dessas instituições, a economia mundial está passando por transformações significativas nos últimos 15 anos: há economias emergentes, como a China e a Índia, crescendo a taxas consistentes mesmo em meio à crise global de 2008/2009, e o centro decisório dos rumos da economia mundial transitou do G8 (grupo dos países mais ricos), na década de 1990, para o G20, na década de 2000, para citar apenas dois exemplos.

As mudanças na economia reverberam nas demandas por mudanças nas estruturas de poder das organizações multilaterais. Por um lado, há Estados que entraram na mesa de discussões da economia mundial nos últimos anos e que não estão satisfeitos com as estruturas vigentes. Esses Estados passaram a reivindicar mudanças ou a propor vias alternativas para as negociações internacionais. É o caso especialmente de Brasil e Índia, que lideram o G20 agrícola na OMC, o qual mira os subsídios agrícolas de Estados Unidos e União Europeia, que distorcem o comércio internacional em seu desfavor. É o caso também da demanda por mudanças que as economias emergentes tentaram obter por meio das reformas do BM e do FMI. Por outro lado, há países centrais insatisfeitos com a chegada de países emergentes e em desenvolvimento à mesa de negociações e com a capacidade que esses países têm demonstrado de, se não definir, ao menos paralisar o curso das decisões. É o caso dos Estados Unidos, que, insatisfeitos com a paralisia a que as demandas do G20 agrícola levaram a OMC, buscam vias alternativas para continuar definindo as regras do comércio internacional. Os Estados Unidos - ao menos até a recente chegada de Donald Trump à presidência - articularam durante anos mega-acordos comerciais que excluem China, Brasil, Rússia e Índia e que, uma vez aprovados, têm o potencial de ditar as novas regras do comércio internacional, deslocando a autoridade da OMC. A União Europeia - ao menos até os recentes movimentos de desintegração regional - também segue o mesmo caminho. Trata-se da mobilização de Estados que tradicionalmente dominaram as estruturas econômicas internacionais, isto é, Estados Unidos e os Estados europeus centrais, que anunciam não pretender ceder poder sem relutância. 
Como entender o conjunto desses movimentos? Este trabalho vale-se do conceito de multilateralismo contestado, formulado por Julia Morse e Robert Keohane (2014), para tentar explicar a natureza das estratégias que os Estados têm adotado ante um cenário de insatisfações relacionadas com os rumos da governança econômica internacional.

O artigo está dividido em quatro partes. Após a introdução, na segunda parte é apresentado o referencial teórico que conforma o que Morse e Keohane chamaram de multilateralismo contestado. Na terceira parte, são trabalhados os elementos que permitem compreender os impasses atuais existentes nos regimes comercial e financeiro internacionais. São esses impasses que levam os Estados a procurar vias alternativas para a construção da nova onda da governança internacional fora das instituições tradicionais em operação. Na quarta parte, analisam-se as coalisões formadas para contestar o multilateralismo representado pelas instituições de Bretton Woods e apresentam-se e discutem-se os resultados da análise a partir do esquema conceitual do multilateralismo contestado. Com esse roteiro, pretende-se apresentar os impasses e as vias alternativas que os descontentes têm construído a partir do referencial do multilateralismo contestado. As considerações finais anunciam uma improvável - mesmo que possível reversão das tendências apontadas no artigo a partir das mudanças anunciadas pelas políticas nacionalistas de Donald Trump nos Estados Unidos e do potencial semelhante existente na França, Reino Unido, Holanda e outros países europeus.

\section{O MULTILATERALISMO CONTESTADO}

Há tempos, a literatura tem enfatizado a cooperação e coordenação promovida pela atuação internacional dos Estados. Em sua formulação mais estruturada, Stephen Krasner (1982) definiu como regimes internacionais um conjunto de princípios, normas, regras e procedimentos de tomadas de decisões, implícitos ou explícitos, de determinada área de relações internacionais, em torno dos quais convergem as expectativas dos atores. Os regimes internacionais envolvem, portanto, um alto nível de cooperação ou ao menos de coordenação entre os Estados.

A história da articulação multilateral internacional é marcada por uma forte ligação com a ideia de cooperação ou, no mínimo, coordenação entre os Estados. As organizações internacionais, frequentemente a face mais visível da articulação multilateral, são vistas como "atores centrais do sistema internacional [...] e mecanismos de cooperação entre Estados e outros atores" (Herz e Hoffmann, 2004, p. 23). As organizações internacionais atuam por uma espécie de autoridade dele- 
gada dos Estados e exercem suas funções de forma vinculada aos objetivos para os quais foram criadas. Em sua atuação, as organizações internacionais revelam a capacidade de fixar significados e difundir normas no sistema internacional (Barnett e Finnemore, 2004, p. 22-34). As iniciativas multilaterais que definem regras, procedimentos, entre outros, são, portanto, historicamente associadas à coordenação e cooperação no ambiente internacional.

Entretanto, uma literatura mais recente tem enfatizado a carga de contestação e o potencial de mudança que as iniciativas multilaterais podem envolver. Essas iniciativas buscam forçar uma alteração nos regimes existentes, como no caso do regime internacional do comércio, ou da propriedade intelectual, ou dos investimentos. Além disso, a dinâmica atual parece revelar que não apenas mudanças nos regimes estão em curso: o peso dos atores internacionais envolvidos nas tentativas de mudança e as novas instituições e fóruns que estes têm criado apontam para um novo quadro. Nele, observa-se o surgimento de iniciativas multilaterais alternativas às existentes e com estas competitivas, que são fomentadas por grupos de Estados insatisfeitos com as instituições multilaterais vigentes e que criam novas instituições ou novos fóruns para desafiá-las.

Buscando construir um arcabouço conceitual para entender essa mudança em curso, Julia Morse e Robert Keohane (2014) propuseram, em Contested multilateralism, um esquema conceitual para compreender a dinâmica de contestação que parece ter movido diferentes iniciativas dos Estados neste século XXI. O esquema parte de duas premissas: (i) que o multilateralismo é persistente e (ii) que ele está em transformação. Os autores indicam então que, para se opor às instituições multilaterais existentes, os Estados o fazem não por meio de iniciativas unilaterais ou bilaterais, mas por meio de outras iniciativas igualmente multilaterais. Daí a situação que emerge ser denominada pelos autores de multilateralismo contestado. Em suas palavras, o multilateralismo contestado emerge da seguinte situação:

Quando coalisões estão insatisfeitas com a operação de um regime internacional em particular, esses atores podem desafiá-lo mudando o foco da criação de regras próprias àquele regime para outras instituições. (Morse \& Keohane, 2014, p. 409, tradução nossa).

Dito de outra forma: o multilateralismo contestado se refere à contestação do multilateralismo corrente, feita por Estados insatisfeitos com o status quo existente, por meio de articulações multilaterais.

O deslocamento da criação de regras de uma instituição internacional pode ser feito para outra instituição já existente ou para outra instituição criada para esse 
fim, isto é, o locus de autoridade para a criação de regras em determinado campo pode ser deslocado para uma instituição que já existe e que pode vir a abarcar a autoridade para criação de novas regras ou uma nova instituição pode ser criada para lidar especialmente com essas novas regras. Caso esse deslocamento tenha força suficiente, ele poderá provocar uma alteração no regime internacional vigente (com o surgimento de novas instituições competentes naquela esfera) ou mesmo o esvaziamento deste regime em benefício das novas instituições que foram criadas.

Na figura 1, pode-se observar o esquema gráfico do multilateralismo contestado.

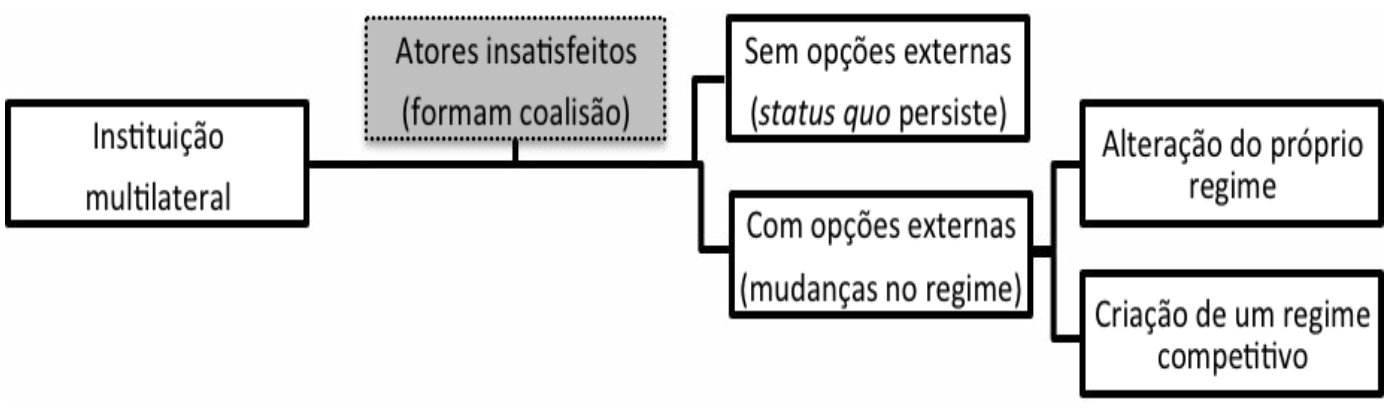

Figura 1 - Esquema gráfico do multilateralismo contestado

Fonte: elaboração da autora a partir de texto de Morse e Keohane (2014).

Para os autores, portanto, a desagregação ou enfraquecimento de instituições multilaterais em função da incompatibilidade de interesses entre grupos internos à sua dinâmica não resulta necessariamente em sua substituição por uma estrutura bilateral ou unilateral. Em outras palavras: as crises dentro de um regime multilateral não resultam em um modelo alternativo bilateral ou unilateral necessariamente. Os desacordos em relação a uma instituição multilateral podem resultar na sua contestação por outras estruturas igualmente multilaterais, que têm potencial para enfraquecer as estruturas vigentes ou mesmo promover seu esvaziamento. $O$ conjunto de situações que emerge quando grupos em disputa propõem a criação dessas outras estruturas multilaterais, que são alternativas ao status quo e que o desafiam, é o que Morse e Keohane chamam de multilateralismo contestado.

Esse esquema conceitual parece explicar a dinâmica que envolve atualmente os regimes internacionais financeiro e comercial que vieram se consolidando desde metade dos anos 1940, com a criação das instituições de Bretton Woods, a partir do fim da Segunda Guerra Mundial. A próxima seção apresenta os aspectos estruturais e os movimentos de contestação multilateral feitos a esses regimes. 


\section{ELEMENTOS PARA COMPREENDER O IMPASSE NOS REGIMES COMER- CIAL E FINANCEIRO INTERNACIONAIS}

A estrutura das grandes organizações internacionais financeiras e comerciais dominantes até hoje no cenário mundial foi criada e progressivamente moldada sob a hegemonia do Ocidente e, mais especificamente, sob a dinâmica de poder única de que dispõem os Estados Unidos (Art, 2008; Gilpin, 1987; Ruggie, 1996). O marco fundacional dessa hegemonia, desenhada institucionalmente, mas assegurada por meio da sua proeminência militar sempre que necessário (Art, 2008), pode ser encontrado nas conferências de Bretton Woods, ao final da Segunda Guerra Mundial. Nesse momento, a pretensão dos Estados Unidos era criar três mecanismos que favorecessem a contínua expansão do comércio mundial e o provimento de recursos financeiros de curto e de longo prazos a países que necessitassem desses suportes. Como materialização institucional dessas pretensões, surgiram o $\mathrm{FMl}$ e o BM. Ambas as organizações foram projetadas para cuidar, respectivamente, da disponibilidade de recursos para países em emergência financeira e do provimento de investimentos para o desenvolvimento. $\mathrm{Na}$ frente comercial, ante a impossibilidade política de se criar uma Organização Internacional do Comércio (OIC), que viabilizasse a contínua expansão do comércio internacional, foi adotado um Acordo Geral de Tarifas e Comércio (GATT, do acrônimo em inglês), um tratado que previa regras de negociação para a progressiva liberalização do setor comercial. Eis os pilares do que passou a ser conhecido como "Sistema de Bretton Woods". Esse sistema fornece as bases institucionais da governança econômica global vigente. No início do século XXI, cada um desses três pilares foi questionado por países em desenvolvimento (PEDs), cujos interesses foram historicamente marginalizados por suas instituições, ou pelos próprios países desenvolvidos (PDs), insatisfeitos com os rumos que os movimentos dos PEDs conseguiram impor à dinâmica de funcionamento institucional.

A presente seção retoma a estrutura de funcionamento e de governança dentro de cada uma dessas organizações do sistema econômico internacional e apresenta a forma como elas vêm sendo desafiadas, a partir de articulações multilaterais, no início deste século.

\subsection{Organização Mundial do Comércio}

Entre 1944 e 1947, durante o mesmo período em que se discutiu a criação do BIRD e do FMI, foi enfatizada a necessidade de criação de uma Organização Internacional do Comércio (OIC). O seu objetivo seria estabelecer diretrizes 
e regular o comércio internacional, evitando uma nova escalada protecionista que mergulhasse o mundo novamente em um conflito mundial. Divergências entre as grandes potências do período, entretanto, dificultaram as negociações. A elas se somou uma barreira decorrente da conjuntura política interna norte-americana, principal ator do comércio internacional à época. Assim, ao invés de uma OIC, os Estados ficaram vinculados comercialmente por um acordo geral - o Acordo Geral de Tarifas e Comércio (General Agreement on Tariffs and Trade-GATT).

O funcionamento do comércio internacional foi organizado sob a égide das regras e dos procedimentos estipulados no GATT, o qual, a partir de 1995, foi transformado em Organização Mundial do Comércio (OMC). As regras que foram criadas e se desenvolveram no marco desse regime internacional eram bem conhecidas da governança comercial mundial no início do século XXI:

i. rodadas de negociação: os países participam de rodadas de negociação para liberalizar progressivamente o comércio. Cada rodada enfrenta uma agenda de temas a serem discutidos de forma que, resolvida uma rodada de negociação, passa-se a outra, com renovada agenda de liberalização comercial (GATT, 1947, Art. XXVIII bis);

ii. cláusula da nação mais favorecida: segundo suas disposições, toda vantagem comercial acordada por qualquer parte contratante do GATT para um país não membro deve ser estendida imediata e incondicionalmente para produtos semelhantes originados de ou destinados aos territórios de todas as partes contratantes do acordo1 (GATT, 1947, Art. I). Esse mecanismo garantia a progressiva redução das tarifas mundiais sobre o comércio internacional ao estender automaticamente uma vantagem comercial conferida a um país a todas as demais partes do acordo;

iii. mecanismo de decisão pelo qual "nada está acordado até que tudo esteja acordado" e no qual cada Estado tem um voto. Apesar de sugerir uma tomada de decisão democrática, com necessária participação de todas as partes, esse esquema não deu mais espaço para os países em desenvolvimento (PEDs). Os países desenvolvidos (PDs) dominaram historicamente a construção de normas no sistema GATT-OMC. As decisões eram tomadas na chamada Green Room por Estados Unidos e União Europeia, aos quais se somavam, com participação mais moderada, Canadá e Japão. Esses eram os quatro membros do chamado QUAD, que acordava entre si o texto que seria depois apresentado aos

1 De forma mais simples: toda vantagem tarifária mais benéfica concedida a um não membro do GATT por um Estado deve ser automaticamente concedida por este Estado aos demais parceiros do GATT. 
demais países e firmado por eles (Kapoor, 2006).

A governança comercial internacional vigente até os primeiros anos da década de 2000, portanto, foi o resultado de uma ordem dominada pelo poder dos Estados Unidos, pelos seus interesses e pelos do mundo ocidental desenvolvido. Os mecanismos estabelecidos lograram liberalizar progressivamente o comércio internacional de produtos industrializados via redução tarifária, mas o mesmo não aconteceu com o setor agrícola, no qual os PEDs detêm vantagens competitivas. Em função desse cenário, na primeira década do século XXI, PEDs como o Brasil, a Índia e a China questionaram os termos das negociações comerciais internacionais e desafiaram a predominância dos Estados Unidos no estabelecimento das regras do jogo do comércio internacional.

A oposição ao sistema de criação e especialmente ao conteúdo dos acordos firmados no âmbito da OMC não foi uma novidade surgida apenas neste século. Há décadas, os PEDs denunciam as assimetrias de interesses contemplados nos acordos do sistema GATT-OMC. A novidade está na persistência da contestação feita por PEDs em coalisão. O momento pontual desse movimento dentro da OMC foi a reunião ministerial de Cancun, realizada em 2003, no âmbito da rodada Doha de negociações comerciais. Antes da reunião, os PDs tinham fechado a sua proposta, dentro da forma de trabalho que as décadas anteriores tinham chancelado. Os interesses dos PDs estavam voltados à adoção de regras sobre não discriminação em tópicos como concorrência, serviços e proteção a investimentos. Por sua vez, os PEDs estavam preocupados em discutir a redução dos subsídios agrícolas (domésticos e à exportação) dos PDs. Para os PEDs, a redução de tarifas e subsídios à agricultura dos PDs, um dos setores menos liberalizados do comércio, deveria ser o tema-chave da rodada.

Nas preparações para a reunião ministerial de Cancun, que ocorreria em 2003, o Brasil se aproximou da Índia para que juntos liderassem a oposição ao projeto de Estados Unidos e União Europeia de postergar as discussões em torno da agricultura e, paralelamente, forçar os PEDs a aceitar uma nova leva de reduções tarifárias. Brasil e Índia passaram a liderar o G20 agrícola, um grupo formado dentro da OMC para questionar a agenda que vinha se desenhando por parte dos PDs. Em sua posição, o grupo se recusava a aceitar mais reduções tarifárias sobre produtos industrializados, enquanto os PDs não fizessem concessões no setor agrícola (da Conceição-Heldt, 2013). Mais que resistir às propostas dos PDs, o bloco de PEDs chegou pela primeira vez a uma reunião ministerial com uma 
postura proativa, focada nos subsídios agrícolas. Chegada a reunião, em 2003, os grupos de negociação já tinham como atores centrais Estados Unidos e União Europeia, de um lado, e Brasil e Índia, de outro (Hopewell, 2015, p. 318-319).

A criação do G20 agrícola foi um marco da contestação da governança comercial mundial vigente. Ela implodiu o sistema anterior de decisões, lançou Brasil e Índia no círculo de decisões da OMC e, pela primeira vez, colocou os Estados Unidos na defensiva, sendo frontalmente demandado por uma proposta dos PEDs. A contestação da estrutura de poder dominante na OMC não passou despercebida à literatura de relações internacionais e economia política internacional, como mostram os textos de Hurrell e Narlikar (2006), Grant (2007) e Eagleton-Pierce (2012).

A tomada de posição chinesa foi a jogada derradeira para a paralisia da rodada de Doha. Hopewell (2015) descreve bem o papel-chave desempenhado pela China: o país apenas ingressou na OMC em 2001, depois de 15 anos de negociações. Para entrar na organização, a China fez substanciais concessões e reformas domésticas. Sua postura foi inicialmente marginal na organização. Isso se manteve até 2008 , quando o país foi chamado às reuniões da Green Room.2 Diferentemente de Brasil e Índia, que construíram seu caminho ativamente até a mesa mais substancial de negociações da OMC, a China foi chamada, por uma decisão dos Estados Unidos e do diretor-geral da OMC, a compor o grupo nevrálgico dos decisores do comércio internacional. A expectativa dos PDs era de que a China se alinhasse às suas posições, advogando a favor da liberalização comercial. Isso deveria colocar pressão para que Brasil e especialmente Índia revissem suas agendas de demandas e cedessem. Da parte dos PDs, o acesso ao mercado chinês era um forte argumento para que suas audiências domésticas aceitassem as concessões que eles deveriam fazer (especialmente na questão de subsídios agrícolas) no curso das negociações (Hopewell, 2015, p. 329-330).

Ao contrário das expectativas, a China - que também tem preocupações com a proteção do setor agrícola - não apoiou a pauta dos PDs e as negociações da Rodada de Doha paralisaram definitivamente (Hopewell, 2015, p. 331). Essa situação permanece até hoje, isto é, por mais de 15 anos a Rodada de Doha está em andamento sem avanços nas negociações. Essa paralisia fez com que os PDs buscassem novas rotas para garantir que a liberalização comercial ocorra dentro dos moldes que querem imprimir ao comércio mundial. Os PDs, especialmente liderados pelos Estados Unidos, passaram a um movimento de contestação do

2 Green Room meetings é como são chamadas as reuniões informais de pequenos grupos de Estados que, apesar da informalidade e da pouca representatividade, definem os termos das mais importantes negociações na OMC. 
multilateralismo da OMC por meio da formação de novos fóruns para discutir e definir regras comerciais. Uma das rotas mais promissoras que viriam a se desenhar eram os Acordos Preferenciais de Comércio (APCs). De acordo com Stephen Hartman (2013, p. 411), desde que se estabeleceu o impasse na rodada Doha, mais de trezentos APCs começaram a ser negociados.

Os APCs apresentaram-se inicialmente como acordos de comércio na forma bilateral ou minilateral que serviriam para que países centrais da arquitetura econômica internacional avançassem suas agendas fora do espaço da OMC, mas a grande marcha para uma nova regulação do comércio internacional parece estar potencialmente contida em APCs expandidos, mais especificamente em mega -APCs. Estes mega-APCs ou acordos megarregionais de comércio são acordos comerciais em larga escala geográfica e em larga escala de regulação econômica. Os exemplos mais paradigmáticos de APCs são a Parceria Transpacífico (TransPacific Partnership - TPP) e o Acordo de Investimento e Comércio Transatlântico (Transatlantic Trade and Investment Partnership - TTIP). A TPP envolve 12 países (Brunei, Chile, Nova Zelândia, Singapura, Austrália, Canadá, Japão, Malásia, México, Peru, Estados Unidos e Vietnã) e seus termos contemplam, entre outras, questões de inovação, investimentos e solução de conflitos. A TTIP segue as linhas da TPP, mas tem como partes os Estados Unidos e a União Europeia.

As palavras do então presidente dos Estados Unidos, Barack Obama, em 2016, revelam o instrumento estratégico (tanto em termos comerciais quanto em termos geopolíticos) que os acordos megarregionais representam para o seu projeto de arquitetura econômica mundial do futuro:

O mundo mudou. As regras estão mudando com ele. Os Estados Unidos, e não países como a China, deveriam escrevê-las. Vamos aproveitar esta oportunidade, aprovar a Parceria Transpacífico, e nos certificarmos que os Estados Unidos não estão carregando a mala, mas segurando a caneta. tradução nossa).

A expectativa dos Estados Unidos é (ou ao menos era, até a chegada de Donald Trump à presidência) de que os APCs criarão incentivos para outsiders, incluindo a China e a Índia, para adaptarem seus próprios standards comerciais. Para usar as palavras do ex-presidente Obama: a expectativa dos Estados Unidos é de que eles continuem a segurar a caneta no desenho das regras globais em assuntos comerciais por meio desses mega-acordos preferenciais de comércio (e não mais por meio da $\mathrm{OMC}$ ). Por meio desses acordos regionais de comércio, a OMC passa a ser frontalmente contestada. 


\subsection{Instituições multilaterais financeiras}

A ascensão chinesa e a onda de crescimento que sua demanda aquecida provocou em grandes países exportadores de matérias-primas vieram acompanhadas de um cenário de difusão do poder mundial. Com a crise financeira global de 2007/2008, essa difusão de poder no sistema internacional econômico se tornou aparente.

O evento inicial para se entender o espaço que surgiu para a mudança no poder de voto no BM e no FMl está na quebra da empresa de serviços financeiros Lehman Brothers e na transmissão sem precedentes da crise financeira dos Estados Unidos para o restante do sistema internacional. O FMI tinha necessidade de obter novos recursos em função do socorro que já tinha prestado à Islândia, Ucrânia, Hungria e ao Paquistão ao longo de 2008. Esses novos recursos não viriam dos Estados Unidos nem da União Europeia, resistentes que estavam de aumentar seus compromissos com organizações internacionais, dados os crescentes déficits que apresentavam. A solução estava nas economias emergentes e nos seus grandes estoques de reservas internacionais. Em troca dos recursos que os PEDs poderiam aportar, em 2009 o G20 financeiro decidiu reformar o BM e o FMI. PDs se comprometeram com a transferência de poder de voto para os PEDs tanto no BM (3\%) quando no FMI (5\%). O principal critério para a distribuição dos votos seria o percentual do Produto Interno Bruto (PIB) mundial de participação de cada país.

Esta seção mostra como as reformas no BM e no FMI não atingiram seus objetivos ostensivos e reforçaram as motivações dos PEDs para a criação de novos espaços de governança financeira internacional que têm o potencial de contestar o multilateralismo tradicional das instituições financeiras de Bretton Woods.

\subsection{Banco Mundial}

O Grupo Banco Mundial (GBM) é uma organização articulada em diferentes componentes, sendo os três mais importantes o Banco Internacional para Reconstrução e Desenvolvimento (BIRD), que representa a principal fonte de empréstimos do grupo, a Associação Internacional para o Desenvolvimento e a Corporação Financeira Internacional. Como é a participação acionária dentro do BIRD que determina a participação dos Estados nas demais estruturas do GBM, é em torno dele (BIRD) que se distribuem as discussões sobre a reforma do Banco Mundial (Vestergaard \& Wade, 2013, p. 154). Da mesma forma se procede neste artigo.

A participação dos Estados no BIRD é organizada por meio de cotas acionárias, em que cada membro detém um dado número de votos proporcional a essa participação. Há dois tipos de elementos na participação acionária: uma parte cor- 
responde aos votos básicos e outra aos votos de cota. Os votos básicos são atribuídos a todos os membros da organização. Os votos-cota obedecem em princípio à regra de que devem refletir a posição do país na economia mundial. Porém, não há um mercado de ações do BIRD. A possibilidade de um Estado subscrever mais ações deve ser decidida por meio de reformas da instituição (Vestergaard \& Wade, 2013, p. 154).

Ao longo do tempo, tanto os votos básicos quanto os votos de cota deixaram de cumprir o papel para o qual foram inicialmente criados. Tome-se os votos básicos, por exemplo. Em 1944, eles correspondiam a mais de $10 \%$ do poder de voto da organização, mas com a entrada de novos países e outras alterações, passaram a corresponder a cerca de $2,8 \%$ do poder de voto da organização no início dos anos 2000 (Vestergaard \& Wade, 2013, p. 154). Os Estados Unidos detêm sozinhos mais de $15 \%$ do poder de voto no BM. Como decisões em temas substantivos (aumento de capital, mudança no tratado constitutivo, etc.) demandam o voto de $60 \%$ dos países membros mais $85 \%$ dos votos, os Estados Unidos detêm poder de veto dentro da instituição. São o único país nessa condição.

Um relatório de 2002 da ONU já registrava a necessidade de reforçar a participação dos PEDs nas organizações multilaterais, mas foi o impulso de natureza econômica oriundo da crise de 2008/2009 que movimentou a vontade política para que alguma alteração ocorresse. A motivação residia no fato de que o dinheiro necessário para novos empréstimos do BM teria que vir dos PEDs. Os PDs não estavam dispostos a repassar mais recursos para a organização, mas tinham interesse em proteger o sistema econômico vigente e suas posições de autoridade dentro desse sistema. Por sua vez, os PEDs detinham grandes reservas e queriam aumentar seu poder dentro das instituições internacionais.

Necessitando das reservas dos PEDs, logo a vontade política surgiu no BIRD e o presidente do GBM, Robert Zoellick, afirmou eloquentemente, em 2009: "a velha ordem se foi" (World Bank, 2009), tradução nossa). A reforma da instituição estava a caminho.

As discussões sobre a reforma envolviam duas questões: (i) o aumento nos votos básicos e (ii) o realinhamento dos votos por cotas. Existiam muitas discussões e pouco consenso sobre o teor e o processo das alterações necessárias. Um dos poucos pontos de concordância - senão o único - era que os países de mais baixa renda deveriam ter maior poder de voto (Vestergaard \& Wade, 2013).

Em 2010, Zoellick anunciou, com o eloquente slogan "Mundo novo, novo Grupo Banco Mundial", as reformas acordadas: 
Um Banco Mundial moderno deve representar as realidades econômicas mundiais do início do século XXI. [...] Estamos aumentando significativamente a voz de países em desenvolvimento dentro do Grupo [Banco Mundial]. Este realinhamento reforça nossa capacidade de dar suporte aos membros mais pobres e demonstra que mais voz para países emergentes e países em desenvolvimento e traz junto maiores responsabilidades para com a solidez financeira do Banco Mundial. (World Bank, 2010, tradução nossa).

Em termos percentuais (Tabela 1), a reforma alterava em mais de três pontos o poder de voto dos países de renda média (fundamentalmente os emergentes) e reduzia em quase quatro pontos o poder de voto dos PDs. Os países de mais baixa renda, apesar de serem os principais tomadores de recursos do BIRD, praticamente não ganharam nenhum poder de voto e continuaram largamente marginalizados. Ironicamente, esses eram os países que deveriam ser mais beneficiados pela reforma.

Tabela 1 - A reforma dos votos (percentual)

\begin{tabular}{|c|c|c|c|c|}
\hline & Antes & $\begin{array}{c}\text { Depois da fase } \\
\text { 1 da reforma }\end{array}$ & $\begin{array}{c}\text { Depois da fase } \\
\text { 2 da reforma }\end{array}$ & $\begin{array}{c}\text { Mudança } \\
\text { acumulada }\end{array}$ \\
\hline $\begin{array}{c}\text { Países de } \\
\text { renda baixa }\end{array}$ & 3,5 & 4 & 3,8 & +0.34 \\
\hline $\begin{array}{c}\text { Países de } \\
\text { renda média }\end{array}$ & 31,2 & 32,1 & 34,5 & $+3,3$ \\
\hline $\begin{array}{c}\text { Países de } \\
\text { alta renda }\end{array}$ & 65,3 & 64,1 & 61,7 & $-3,7$ \\
\hline
\end{tabular}

Fonte: Vestergaard e Wade (2014).

Os movimentos dos Estados em relação à redistribuição de votos demonstram que não há cessão do poder na governança econômica internacional sem relutância. Dois processos revelam que os PDs não cederiam participação facilmente. O primeiro diz respeito a uma artimanha de reclassificação de países usada nas primeiras fases da reforma. Países claramente desenvolvidos, como a Coreia do Sul, emprestadores de recursos para o BIRD, foram reclassificados e rebaixados de status, causando distorções. Essa reclassificação de países é responsável por parte da perda de quase quatro pontos percentuais dos países de alta renda, conforme indicado na tabela 1. O uso dessa artimanha fornece um quadro final de transferência de votos que mascara a real transferência de poder entre os grupos de países.

O segundo movimento diz respeito a ações tomadas pelos Estados após o final das fases de reforma. Ele se relaciona com as subscrições de capital possibilitadas a PDs e das quais estes países poderiam fazer uso, revertendo um quadro de perda de poder de voto. No início das reformas, a ideia que as inspirava era de 
que os votos deveriam ser proporcionais ao peso econômico dos países, isto é, deveriam manter alguma proporcionalidade com o que o PIB do país representa em relação ao PIB mundial. Encerrada a fase 2 da reforma, os PDs conseguiram manter uma participação maior que $60 \%$ no poder de voto no BM. Mais que isso, fazendo uso dos direitos de subscrição de capital adicionais, em agosto de 2012, Japão, Canadá, Alemanha, Reino Unido e França aumentaram suas ações votantes. A situação é tal que Japão e Canadá têm, hoje, mais votos do que tinham antes da reforma. Por sua vez, Alemanha, Reino Unido e França reverteram completamente suas perdas (Tabela 2).

Tabela 2 - Alterações percentuais na distribuição do poder de voto no Banco Mundial

\begin{tabular}{|l|l|l|l|}
\hline & $\begin{array}{l}\text { De acordo com as } \\
\text { reformas de 2010 }\end{array}$ & $\begin{array}{l}\text { Ações votantes atuais } \\
\text { pós subscrições } \\
\text { adicionais }\end{array}$ & Mudança \\
\hline PDs & 52,83 & 55,87 & $+3,04$ \\
\hline PEDs & 47,21 & 44,13 & $-3,11$ \\
\hline
\end{tabular}

Fonte: Vestergaard e Wade (2014).

O cenário de reversão das perdas do poder de voto dos PDs é tão dramático que, ao contrário de todo o espírito das reformas, chega a representar uma perda adicional do poder de voto dos PEDs ao final do processo. Como apontam Vestergaard e Wade (2014, p. 21-22), os modestos ganhos anunciados no acordo de 2010 estavam sujeitos a que países de renda alta não subscrevessem o número total de cotas que poderiam requisitar. Não foi o que aconteceu, e o resultado é que não só as mudanças prometidas na revisão de 2010 não se converteram em mudanças reais no poder de voto dos PEDs, como também esses países acabaram com menor poder de voto do que o acordado em 2010.

Tanto para o Banco Mundial quanto para o FMI, como se verá adiante, a crise representou uma possibilidade de essas instituições retomarem um volume de negócios e uma posição de relevo no cenário internacional. Ali Barak Güven (2012) explica essa situação: depois de um período de crescimento econômico mundial, reduziu-se a dependência de países semiperiféricos bem integrados à economia mundial dos empréstimos oficiais. O portfólio de empréstimos do Banco Mundial para o período 1999-2003, por exemplo, ficou muito abaixo do realizado nos períodos anteriores. Para se ter uma ideia do que a crise representou em termos de recuperação do papel das instituições financeiras econômicas, de 2008 a 2009, os empréstimos do BIRD dobraram. Para o FMI, os mais de setenta acordos firmados entre setembro de 2008 e dezembro de 2011 representaram um cresci- 
mento de 240 vezes nos novos compromissos assumidos em 2011 comparados aos de 2007 (Güven, 2012, p. 872-873).

Some-se a essa redução da atividade financeira o crescimento do escrutínio público sobre os projetos de estabilização ortodoxa e programas de ajustes e tem-se o quadro problemático em que se encontravam as grandes instituições financeiras internacionais quando a crise desencadeou-se em 2008/2009 (Güven, 2012, p. 872). Quem tinha recursos para emprestar eram os PEDs, que em troca receberiam o reconhecimento de um peso maior na definição dos rumos das instituições. Daí a propositura das reformas com ares de mudanças drásticas na governança econômica internacional em favor dos PEDs. Como visto, no caso do Banco Mundial, as mudanças foram mera retórica e o resultado do processo, inclusive, aprofundou a diferença de poder de voto entre PDs e PEDs. Com o FMI, o processo não seria muito diferente.

\subsection{Fundo Monetário Internacional}

A estrutura institucional do FMI é organizada de forma que a quantidade e a distribuição de cotas balizam a contribuição financeira de cada Estado, o acesso aos recursos do fundo e o poder de voto de cada um.

Em meio à crise financeira de 2008/2009, sentiu-se a necessidade de incrementar os recursos do FMI, para que a organização recuperasse sua capacidade de conceder empréstimos. Na reunião do G20 financeiro, em 2009, em Londres, foi acordado que os recursos do FMI seriam triplicados. A ideia era restaurar a capacidade de gerenciamento de crises financeiras do FMI e recuperar a legitimidade da organização - que de longa data é acusada de desequilíbrio na representação dos PEDs em relação aos PDs (Lesage Debaere, Dierckx e Vermeiren, 2013).

Dadas as condições políticas e financeiras dos Estados Unidos e da Europa, a conclusão lógica para a origem dos novos recursos do fundo estava nos BRICS (Brasil, Rússia, Índia, China e África do Sul). Do lado dos Estados Unidos, a liberação de mais verbas para o financiamento de organizações multilaterais não seria aprovada pelo Congresso. Do lado europeu, não se poderia contar com um incremento financeiro dos países que já lidavam com dificuldades de países do bloco ou do seu entorno. Era necessário recorrer aos recursos dos PEDs e especialmente de alguns mercados emergentes neste grupo, que vinham em onda de crescimento desde o início do século e tinham acumulado grandes reservas de moedas internacionais. Por sua vez, esses Estados desejavam aumentar suas cotas e seu poder de voto no FMI. Logo, existiam as condições para que uma re- 
forma tivesse lugar (Lesage et al., 2013).

Os BRICS estariam entre os principais fornecedores de reservas para recuperar a capacidade de ação do fundo. Em troca, seria feita uma reforma na instituição com redistribuição de assentos no Conselho Executivo e com redistribuição de cotas e poder de voto em favor do Sul Global. Antes mesmo de concluído o processo de negociação das reformas, Japão, China e um grande número de economias emergentes aportaram recursos ao fundo, na forma de Novos Mecanismos de Empréstimo3 (designados na literatura por sua redação em inglês New Arrangements to Borrow - NABs) (Vestergaard \& Wade, 2014, p. 10). Os NABs não conferiam aos emprestadores dos recursos ganho de cotas ou direito a voto. Por que, então, os países cederam recursos nessas condições?

Lesage et al. (2013) explicam que esses empréstimos na forma de NABs se justificam porque, primeiro, é mais seguro emprestar por meio de uma instituição multilateral do que por mecanismos bilaterais; segundo, porque por meio de uma instituição multilateral melhor se impõem ajustes que se consideram necessários aos tomadores dos empréstimos; e terceiro, porque esses Estados estavam interessados em auxiliar em meio à emergência financeira, já que suas economias foram afetadas pela queda na demanda em função da crise de 2008/2009. Em troca dos recursos aportados, esses Estados conseguiam reforçar o compromisso dos demais membros da organização com a reforma do fundo.

Em outubro de 2010, o processo de reforma foi concluído com a adoção de um pacote de mudanças que compreenderam o aumento de cotas, a reforma na sua distribuição e mudanças no Conselho Executivo.

Saudando o acordo que anunciava reformas no FMI, o seu diretor-geral, Dominique Strauss-Kahn, afirmou:

Este acordo histórico é a maior revisão fundamental da governança nos 65 anos de história do Fundo e a maior mudança de influência em favor dos mercados emergentes e dos países em desenvolvimento em reconhecimento ao seu crescente papel na economia global. (IMF Press Release, 2010, tradução nossa).

Kahn se referia à mudança que as reformas significavam em favor dos países em desenvolvimento. Em termos gráficos e usando as classificações do fundo, os Mercados Emergentes e Países em Desenvolvimento (MEPEDs) - que neste trabalho estão sendo agrupados sob a designação PEDs - ganharam 6,2\% de cotas-parte das Economias Avançadas (EAs) - que aqui são chamados de PDs

3 NABs: são fundos de reservas criados para reforçar a condição financeira e, portanto, a capacidade de empréstimo do FMI. Em 2010, em cooperação com os demais países do BRIC (Rússia, Índia e China), o Brasil oficializou a participação nos NABs do FMI. 
- com a reforma, equilibrando melhor o quadro de representação em termos de cotas, como mostra a figura 1:

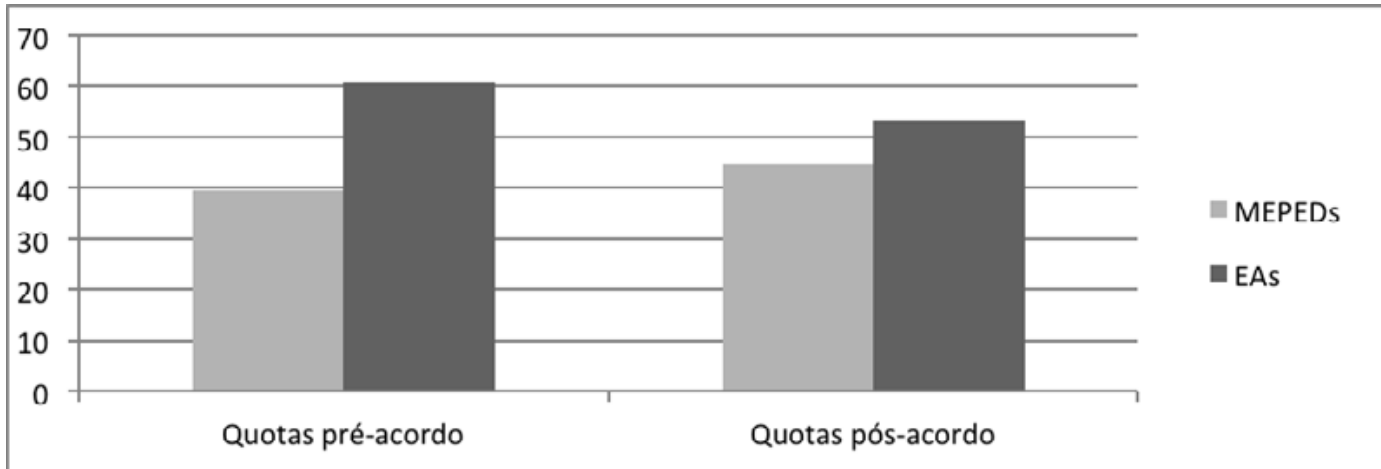

Figura 1 - Alterações de cotas-parte (\%)

Fonte: elaborada com base em Lesage et al. (2013).

As palavras entusiasmadas de Strauss-Kahn e esse aparente movimento em direção a um equilíbrio na representação se desfizeram ao se analisar mais detidamente as mudanças feitas. Dos $6,2 \%$ de cotas-parte que ganharam os MEPEDs, somente $2,6 \%$ vieram das EAs. O restante dessa redistribuição é apenas aparente, pois veio de uma nova classificação de países - estratagema também utilizado na reforma do BIRD, como se viu anteriormente. No processo de reforma, Coreia do Sul e Singapura, que eram consideradas Economias Avançadas pelo próprio FMI, conforme seu relatório de 2010 , foram colocadas no grupo dos MEPEDs. Com isso, o que esses países detinham em cotas-parte deixou de contar para o grupo das Economias Avançadas e passou a somar no grupo dos MEPEDs (Lesage et al., 2013, p. 11).

Em termos de poder de voto dentro do FMI, a situação dos países mais poderosos dentro da estrutura da organização pouco se alterou. Na relação entre poder de voto e PIB (Tabela 3, a seguir), os Estados Unidos perderam apenas 0,02 pontos percentuais. É verdade que, em termos de participação no PIB mundial, os Estados Unidos estão levemente sub-representados no FMI, mas a posição do país é a mais bem resguardada: mesmo depois da reforma, o país mantém praticamente intocado seu percentual de $16,5 \%$ de cotas, o que the confere poder de veto sobre as decisões do fundo, inclusive após a reforma. Os Estados Unidos são o único país nessa condição. Os BRICS, mesmo após as reformas, mantêmse sem poder de veto mesmo agindo em bloco. Sua representação no FMI em relação à sua participação na economia mundial também faz dos BRICS o grupo mais sub-representado entre os que contribuem com o FMI. Por fim, a União Euro- 
peia dos 5 (UE5), composta por Alemanha, França, Reino Unido, Itália e Espanha, mesmo perdendo um pouco do poder de voto, mantém-se como o grupo mais sobrerrepresentado em termos de poder de voto na comparação do seu PIB com o PIB do conjunto dos BRICS. Para usar a imagem criada por Vestergaard e Wade (2014, p. 13), o dólar de PIB que a UE5 aporta ao FMI vale mais que o dólar de PIB que os BRICS aportam.

Tabela 3 - Evolução do poder de voto ao longo da reforma (\%)

\begin{tabular}{|c|c|c|c|c|c|}
\hline & $\begin{array}{c}\text { Votos antes } \\
\text { da reforma } \\
\mathbf{2 0 1 0}\end{array}$ & $\begin{array}{c}\text { Votos com } \\
\text { reformas de } \\
\mathbf{2 0 1 0}\end{array}$ & $\begin{array}{c}\text { Participação } \\
\text { no PIB total }\end{array}$ & $\begin{array}{c}\text { Poder de } \\
\text { voto/PIB } \\
\text { (antes) }\end{array}$ & $\begin{array}{c}\text { Poder de voto/ } \\
\text { PIB } \\
\text { (pós-reformas) }\end{array}$ \\
\hline EUA & 16,75 & 16,47 & 20,53 & 0,82 & 0,80 \\
\hline UE5 $^{*}$ & 19,18 & 18,28 & 15,31 & 1,25 & 1,19 \\
\hline BRICS & 11,03 & 14,13 & 25,15 & 0,44 & 0,56 \\
\hline
\end{tabular}

Fonte: elaborada com base em Vestergaard e Wade (2014).

Por fim, a reforma do Conselho Executivo resultou num acordo em que Bélgica e Holanda ocuparão um assento de forma alternada; a Suíça irá alternar sua participação em um assento com a Polônia; a Turquia entrará no Conselho Executivo num esquema de alternância no assento com a Hungria e a República Checa; e os Estados Bálticos também se beneficiarão por terem a participação incluída em um esquema rotativo. Como destacam Lesage et al. (2013, p. 13): "[...] as mudanças no Conselho Executivo apenas beneficiam Estados (candidatos a) membros da União Europeia, o que não é obviamente o espírito do acordo de 2010".

Nenhuma das mudanças promovidas pelas reformas de 2009-2010 no FMI pode ser considerada como ganho significativo para os países emergentes. Mesmo considerando os ganhos dos BRICS em termos de cotas-parte ou poder de voto, ainda que aja em bloco, o grupo não detém poder de veto no fundo. No processo dessas reformas, ficou claro que alguns países ou grupos de países, como os Estados Unidos, o grupo de Alemanha, Reino Unido, França, Itália e Espanha, e mesmo o grupo de países europeus menores, como Bélgica, Holanda, Suécia e Suíça, detêm grande poder institucional para bloquear ou evitar uma reforma da organização que Ihes acarrete uma perda substancial de poder.

De forma conclusiva, a tabela 4 resume o resultado concreto das reformas anunciadas no auge da crise dos anos 2008/2009 em relação ao desenvolvimento do poder de voto para PDs e PEDs. Nela se percebe que o poder de voto agregado que se esperava distribuir em 2009 em favor dos PEDs foi progressivamente se diluindo. Cinco anos depois das reformas, pelos diversos mecanismos descritos 
anteriormente, o poder de voto em relação ao PIB tinha diminuído para os PEDs em relação aos PDs, em aberto contraste com o espírito das mudanças que deveriam, no mínimo, ter se consolidado.

Tabela 4 - Poder de voto em relação ao PIB para o Banco Mundial e o FMI com base nas reformas idealizadas em 2009 e cinco anos após o anúncio ${ }^{4}$

\begin{tabular}{|c|c|c|c|c|}
\hline & \multicolumn{2}{|c|}{ Banco Mundial } & \multicolumn{2}{|c|}{ FMI } \\
\hline & $\begin{array}{l}\text { Poder de voto } \\
\text { em relação ao } \\
\text { PIB em } 2009\end{array}$ & $\begin{array}{c}\text { Poder de voto } \\
\text { em relação ao } \\
\text { PIB em } 2014\end{array}$ & $\begin{array}{l}\text { Poder de voto } \\
\text { em relação ao } \\
\text { PIB em } 2009\end{array}$ & $\begin{array}{c}\text { Poder de voto } \\
\text { em relação ao } \\
\text { PIB em } 2014\end{array}$ \\
\hline PDs & 0,982 & 1,094 & 1,015 & 1,132 \\
\hline PEDs & 1,027 & 0,903 & 0,975 & 0,858 \\
\hline
\end{tabular}

Fonte: Vestergaard e Wade (2014, p. 14, tradução nossa).

A literatura acadêmica já apontou que algumas instituições congelam a assimetria de poder existente entre os fundadores da organização no momento de sua criação, conferindo a determinados Estados privilégios e benefícios, de tal forma que pode ser impossível ou muito custoso mudá-la (Barnett \& Duvall, 2005, p. 52; Fioretos, 2011, p. 387). No FMI e no BIRD, estão bons exemplos dos custos e da dificuldade de mudanças estruturais institucionais.

\section{COALISÕES DE CONTESTAÇÃO AO MULTILATERALISMO}

O início do século XXI chegou com grandes PEDs esperando uma maior participação nas instituições econômicas multilaterais mundiais, seja com relação à definição do conteúdo das decisões (OMC), seja na composição de órgãos e poder de voto (BIRD e FMI). Na OMC, onde Índia, Brasil e China firmaram posição na contestação aos PDs, o processo de negociações por rodadas encontra-se paralisado há quase duas décadas. No BIRD e no FMI, durante o processo de reformas póscrise de 2008/2009, seus mais altos funcionários expressaram grande expectativa nas mudanças que seriam adotadas. Seguindo uma lógica setorial, era de se esperar que as reformas refletissem o aumento do peso das economias emergentes no cenário internacional neste início de século. Como visto na seção anterior, não foi o que aconteceu. Nem no BIRD nem no FMI as reformas significaram uma significativa transferência de poder dos PDs para os PEDs. Entre estes últimos, nem mesmo as economias emergentes, representadas em seu grupo mais conhecido, os BRI$\mathrm{CS}$, tiveram suas posições institucionais alteradas com as reformas promovidas.

\footnotetext{
$4 \quad$ Conforme anunciam os autores em seu trabalho, os dados da tabela para o Banco Mundial em 2009 são baseados nas participações de voto após a fase 1 de reformas (após 2008); para o FMI, são baseados na situação pós-reforma de 2008. O PIB para 2008 e 2014 é considerado como uma combinação 50/50: 50\% PIB e $50 \%$ PIB paridade do poder de compra (PIB ppc).
} 
Güven (2012, p. 870) também entende como limitadas as reformas de 2010 e enfatiza que, diferente dos abalos anteriores da ordem econômica internacional, que provocaram significativas adaptações no BM e no FMI, a crise de 2008/2009 não provocou nenhuma adaptação substancial. Os choques do petróleo e a crise da dívida, nas décadas de 1970 e 1980, foram importantes para cimentar o receituário liberal ortodoxo nas instituições; a crise dos mercados emergentes dos anos 1990 levou ao revisionismo do liberalismo vigente, mas as práticas do BM e do FMI pós-crise dos anos 2000 não mostram nenhuma diferença substancial em relação ao período pré-crise.

Porém, seria ingênuo e contra os fatos que se apresentam diariamente pensar que a governança econômica internacional mantém-se substancialmente a mesma de vinte anos atrás, mas entre as transformações em curso não está a reorientação do conteúdo do tratamento que as instituições econômicas internacionais dão ao desenvolvimento, nem uma reorientação da governança econômica mundial para um mundo unipolar. A transformação em curso ocorre em outra esfera. O fracasso na efetivação de mudanças nas instituições econômicas multilaterais tem sido respondido pelos países por meio do recurso a outros fóruns ou instituições multilaterais. Em outras palavras: o multilateralismo está sendo contestado com mais multilateralismo.

No caso da OMC, em que mudanças de conteúdo estão sendo cobradas, o modelo encontra-se paralisado. A atual rodada de negociações não avança há quase vinte anos e não há sinais de que avançará no futuro próximo. Em seu lugar, os Estados que querem avançar o processo de liberalização comercial mantendo o controle das regras do jogo têm procurado construir a nova geração de regras da liberalização comercial por meio dos mega-acordos comerciais, dentre os quais se destacam a Parceria Transpacífico (Transpacific Partnership - TPP) e a Parceria Transatlântica de Comércio e Investimento (Transatlantic Trade and Investment Partnership - TTIP):

Os passos mais promissores em direção à liberalização comercial são os mega-acordos regionais entre parceiros comerciais chave, encabeçados pelos Estados Unidos, que incluem a recentemente negociada Parceria Transpacífico e a planejada Parceria Transatlântica de Comércio e Investimento. (Patrick \& Roberts, 2016, tradução nossa).

Em outras palavras: insatisfeitos com a impossibilidade de aprofundar a liberalização comercial em função do bloqueio promovido na OMC pelo G20 agrícola, os países centrais buscam avançar a liberalização criando novos fóruns multilaterais, como, por exemplo, o TPP e o TTIP. 
No caso do sistema financeiro internacional, a reação multilateral vem de outro grupo de insatisfeitos. Percebe-se que, no caso do BIRD e do FMI, os Estados que detêm poder institucional para barrar alterações estruturais mais significativas fazem-no e mantém o status quo praticamente inalterado. Em seu lugar, os insatisfeitos PEDs, especialmente os mercados emergentes, carreados pela força econômica da China, engajam-se em iniciativas multilaterais alternativas, como o Novo Banco de Desenvolvimento (NBD, ou Banco dos BRICS) e o Fundo Contingencial de Reservas (FCR). Neste caso, não se percebe a vontade dos PEDs em criar regras substancialmente opostas ou diferentes daquelas praticadas pelo FMI ou pelo BIRD, isto é, não há nenhum sinal de que as condições dos financiamentos feitos pelo NBD ou os empréstimos feitos pelo FCR, por exemplo, terão condicionantes mais flexíveis. Apesar de algumas diferenças que podem ser notadas, a tônica das contestações dos PEDs nessas novas instituições ou fóruns está nas suas estruturas de governança.

Em todos os casos, portanto, o multilateralismo é persistente, o que corresponde à premissa da qual Morse e Keohane (2014) partem para formular a sua reflexão sobre o multilateralismo contestado. Ao observar, de um lado, a formação de acordos megarregionais de comércio e, de outro, instituições e fóruns criados pelos mercados emergentes, percebe-se que o movimento em curso é de contestação dos regimes multilaterais vigentes, por meio de novas articulações multilaterais. Os insatisfeitos formam grupos e coalisões que se apresentam como espaços alternativos de gestão e suporte da estrutura econômica mundial. Esses novos arranjos multilaterais emergentes contestam a estrutura ou o conteúdo das instituições vigentes com potencial para, no futuro, alterá-las.

O panorama dos grandes regimes econômicos atuais e suas contestações multilaterais podem ser resumidos conforme a tabela 5. Nas três grandes instituições econômicas multilaterais, existe um impasse criado por interesses divergentes quanto ao conteúdo em discussão (OMC) ou quanto à transferência efetiva de poder (BIRD e FMI). Nas três, grupos insatisfeitos com o impasse têm se organizado em torno de coalisões com maior peso que o dos Estados Unidos (no caso da $\mathrm{OMC}$ ) ou da China (nos casos de BIRD e FMI). Em resposta à insatisfação, essas coalisões promovem novas iniciativas multilaterais: acordos megarregionais, para o caso do comércio, e novos fundos e instituições financeiras, para o caso do sistema financeiro. Em todos os casos, as coalisões se organizam para contestar a instituição multilateral a partir do ambiente externo, com potencial de criação de novos regimes ou de alteração nas regras do regime existente. 
Tabela 5 - Panorama dos impasses e das reações que revelam o multilateralismo contestado

\begin{tabular}{|c|c|c|c|}
\hline Impasse & OMC & BM & FMI \\
\hline $\begin{array}{c}\text { PDs e PEDs } \\
\text { com agendas } \\
\text { de conteúdo } \\
\text { divergentes }\end{array}$ & $\begin{array}{c}\text { Resistência na } \\
\text { alteração de poder } \\
\text { relativo }\end{array}$ & $\begin{array}{c}\text { Resistência na } \\
\text { alteração de poder } \\
\text { relativo }\end{array}$ \\
\hline $\begin{array}{c}\text { Coalisões } \\
\text { insatisfeitas que } \\
\text { reagem pela } \\
\text { via multilateral } \\
\text { externa* }\end{array}$ & $\begin{array}{c}\text { Articulação via } \\
\text { Estados Unidos }\end{array}$ & $\begin{array}{c}\text { Articulação via } \\
\text { China }\end{array}$ & $\begin{array}{c}\text { Articulação via } \\
\text { China }\end{array}$ \\
\hline $\begin{array}{c}\text { Ações de } \\
\text { contestação } \\
\text { multilateral }\end{array}$ & $\begin{array}{c}\text { Acordos comerciais } \\
\text { megarregionais - } \\
\text { TPP, TPPI }\end{array}$ & $\begin{array}{c}\text { Novo Banco de } \\
\text { Desenvolvimento }\end{array}$ & $\begin{array}{c}\text { Fundo Contingencial } \\
\text { de Reservas }\end{array}$ \\
\hline
\end{tabular}

Fonte: elaboração própria.

*Refere-se à articulação multilateral fora da instituição em que se dá a insatisfação.

De acordo com o modelo de Morse e Keohane (2014), se essas coalisões forem bem-sucedidas, o efeito sistêmico poderia ser de criação, reforço ou expansão de um regime internacional. Para os casos deste trabalho, acredita-se que, em sendo bem-sucedidas, essas contestações multilaterais levarão ao aumento da complexidade do regime internacional econômico.

\section{CONSIDERAÇÕES FINAIS}

O século XXI está assistindo ao enfraquecimento da hegemonia ocidental (entendida aqui como Estados Unidos e União Europeia) sobre a ordem internacional. $\mathrm{Na}$ esfera das grandes organizações internacionais econômicas, essa transformação vem se fazendo sentir.

$\mathrm{Na}$ OMC, o G20 agrícola se organizou na tentativa de se opor ao sistema de subsídios agrícolas dos PDs. Ante o impasse em que se encontra a OMC, liderados pelos Estados Unidos, foram sendo erguidos grandes acordos comerciais, fora da égide da organização: os mega-acordos comerciais TPP e TTIP.

No FMI e no BM, os emergentes, especialmente os BRICS, demandaram reformas de governança. O Ocidente respondeu com reformas de fachada, que em nada ou muito pouco alteraram a posição de poder entre os países.

Em suma: mesmo com reformas e contestações de fora dos Estados centrais, as organizações internacionais econômicas sofreram nenhuma ou quase nenhuma mudança nos últimos anos, seja em termos de agenda, seja em termos de governança. A OMC continua paralisada, e as reformas do BM e do FMI fizeram 
com que os países desenvolvidos, como grupo, aumentassem seu poder de voto relativo ao PIB, em clara oposição ao que era o espírito das reformas anunciadas no auge da crise de 2008/2009.

Além da constatação de que o Ocidente não irá abrir mão da hegemonia conquistada nas instituições econômicas multilaterais sem relutância, existem muitos pontos a serem investigados para que se compreendam as mudanças que estão em curso e os rumos aos quais elas levam. Ante o cenário esboçado, porém, o referencial do multilateralismo contestado oferece um quadro teórico no qual se podem compreender as estratégias dos países. Aplicados aos casos de OMC, BIRD e FMI, pode-se afirmar que, independente da direção para a qual apontam, os movimentos dos Estados revelam uma estratégia compartilhada: agir por meio de grupos que contestam o multilateralismo vigente por meio de novas estruturas multilaterais. Permanece, portanto, mesmo em meio às transformações econômicas deste início de século, a tendência pelo multilateralismo.

Como ressalva, vale a pena mencionar as tendências econômicas nacionalistas esboçadas no primeiro mês da administração de Donald Trump como presidente dos Estados Unidos e as possíveis reversões do processo de integração europeia (com o Brexit votado em 2016 e os possíveis Frexit, Grexit e outros "exits" que podem ainda se manifestar em meio à onda de nacionalismos que agita a Europa). Essas tendências têm o potencial para reverter o trabalho nas frentes multilaterais que os Estados Unidos e outros Estados europeus vinham construindo especialmente no setor comercial. Trata-se de algo novo, que se afasta do apoio ao institucionalismo liberal que os Estados Unidos sempre garantiram ao sistema de instituições multilaterais desde o fim da Segunda Guerra Mundial, como bem apontou Perry Anderson (2015).

Essa tendência de voltar-se para si e para as questões domésticas, retirando apoio das formulações das regras mundiais elaboradas por meio das grandes organizações internacionais (como OMC) ou dos fóruns multilaterais (como vinha se desenhando ser a TPP, da qual Trump retirou os Estados Unidos, por meio de decreto assinado em 23 de janeiro de 2017), pode frear a participação dos Estados Unidos na construção das regras do grande jogo econômico internacional. Esse movimento, porém, não reverterá a contestação feita ao multilateralismo por meio das novas articulações multilaterais que vêm sendo erguidas, como o Novo Banco de Desenvolvimento, por exemplo. Antes pelo contrário, em um jogo em que o Ocidente parecia estar com a mão de cartas bem formada, a retirada dos Estados Unidos e a potencial retirada de países centrais europeus de acordos megarregionais recoloca 
na mesa as cartas do jogo, permitindo uma reversão do cenário desfavorável que vinha sendo criado para países como a China. Se essas contestações vão transformar os regimes econômicos internacionais vigentes ou criar novos regimes que substituirão os antecedentes ainda é incerto. Menos incerta parece ser a estratégia do caminho que será tomado: a via deve ser a multilateral.

\section{REFERÊNCIAS}

Anderson, P. (2015). A política externa norte-americana e seus teóricos. São Paulo: Boitempo Editorial.

Art, R. J. (2008). America's grand strategy and world politics. Nova York: Pearson Longman.

Barnett, M., \& Duvall, R. (2005). Power in international politics. International Organization, 59(01), 39-75.

Barnett, M., \& Finnemore, M. (2004). Rules for the world: International organizations in global politics. Ithaca: Cornell University Press.

da Conceição-Heldt, E. (2013). Emerging powers in WTO negotiations: The domestic sources of trade policy preferences. The International Trade Journal, $27,431-449$.

Eagleton-Pierce, M. (2012). Symbolic Power in the World Trade Organization. Oxford: OUP Oxford.

Fioretos, O. (2011). Historical institutionalism in international relations. International Organization, 65(02), 367-399.

GATT. (1947). General Agreement on Tariffs and Trade. World Trade Organization. Retrieved from https://www.wto.org/english/docs_e/legal_e/gatt47_e.pdf

Gilpin, R. (1987). The political economy of international relations: Princeton, NJ: Princeton University Press.

Grant, W. (2007). The shift from duopoly to oligopoly in agricultural trade. The WTO After Hong Kong: Progress in, and Prospects for, the Doha Development Agenda, 169.

Güven, A. B. (2012). The IMF, the World Bank, and the global economic crisis: exploring paradigm continuity. Development and Change, 43(4), 869-898.

Hartman, S. W. (2013). The WTO, the Doha Round Impasse, PTAs, and FTAs/ RTAs. The International Trade Journal, 27, 411-430.

Herz, M., \& Hoffmann, A. R. (2004). Organizações internacionais: História e práticas. Rio de Janeiro: Elsevier.

Hopewell, K. (2015). Different paths to power: The rise of Brazil, India and China 
at the World Trade Organization. Review of International Political Economy, 22(2), 311-338.

Hurrell, A., \& Narlikar, A. (2006). A New Politics of Confrontation? Brazil and India in Multilateral Trade Negotiations $\square$. Global Society, 20(4), 415-433.

IMF Press Release. (2010). IMF Executive Board Approves Major Overhaul of Quotas and Governance. International Monetary Fund. Retrieved from http:// www.imf.org/external/np/sec/pr/2010/pr10418.htm

Kapoor, I. (2006). Deliberative Democracy and the WTO. Review of International Political Economy, 11(3), 522-541.

Krasner, S. D. (1982). Structural causes and regime consequences: regimes as intervening variables. International Organization, 36(02), 185-205.

Lesage, D., Debaere, P., Dierckx, S., \& Vermeiren, M. (2013). IMF reform after the crisis. International Politics, 50(4), 1-26.

Morse, J. C., \& Keohane, R. O. (2014). Contested multilateralism. The Review of international organizations, 9(4), 385-412.

Obama, B. (2016, Maio 02). The TPP would let America, not China, lead the way on global trade, The Washington Post.

Patrick, S. M., \& Roberts, M. M. (2016, Maio 17). Why the State of the World Is Better Than You Think. World Politics Review.

Ruggie, J. G. (1996). Constructing the World Polity: Essays on international institutionalisation. London: Routledge.

Vestergaard, J., \& Wade, R. H. (2013). Protecting power: How Western states retain the dominant voice in the World Bank's governance. World Development, 46, 153-164.

Vestergaard, J., \& Wade, R. H. (2014). Out of the woods: Gridlock in the IMF, and the World Bank puts multilateralism at risk: DIIS Reports, Danish Institute for International Studies.

World Bank. (2009). The World Banck group beyond the crisis. Remarks of Robert B. Zoellick, President, Board of Governors of the World Bank Group, The World Bank Group, Istanbul, Turkey. October 6, 2009. Istanbul, Turkey: The World Bank Group. Retrieved from http://web.worldbank.org/WBSITE/ EXTERNAL/COUNTRIES/SOUTHASIAEXT/0,,contentMDK:22340541 menuPK:158845 pagePK:2865106 piPK:2865128 theSitePK:223547,00.html

World Bank. (2010). New world, new World Bank Group: Syntesis paper. Washinghton, DC: World Bank Group. 